\title{
THE EFFICIENCY OF IRRIGATION AND VARIETY ON THE HARVEST RATIO OF THREE COTTON TYPES (Gossypium hirsutum L.)

\author{
Galina Gospodinova ${ }^{1}$, Antoniya Stoyanova ${ }^{2}$, Velika Kuneva ${ }^{3}$
}

\begin{abstract}
The purpose of this research is to investigate the impact of variety and irrigation on three cotton types, and to study the effectiveness of irrigation on the productivity of these cotton types which were fed by different norms of mineral nutrition. To assess the impact of soil humidity and fertilizer amount, we set up a field trial with three varieties of cotton. The field experiment was carried out within the Faculty of Agriculture, Trakia University, Stara Zagora, Bulgaria between 20182019. A two way factorial ANOVA (with variety and irritation as factors) suggested a significant main effect of irrigation $(\mathrm{p}<.001)$. Variety showed the strongest impact on the differences in "flowering" of cotton which were $64 \%$ in 2018 and $41 \%$ for 2019 respectively. We established an efficiency coefficient (KEF) representing the ratio of the additional harvest and the actual irrigation rate. The KEF of irrigation water varied depending on the cotton varieties and the levels of fertilization. The highest values of KEF were recorded after fertilization by $\mathrm{N}_{8}$ as given by units of cultivar Helius $(\mathrm{EF}=0.67)$. The effect of irrigation, expressed as a harvest per unit of irrigation water considerably varied over years. It was established as a ratio between the irrigation rate and the additional cotton produce. At zero fertilization Helius, each cubic meter of water carried an average 2.24 kilograms of cotton harvest over two years. Optimizing the water supply and fertilizing with $\mathrm{N}_{16}$ provided 2.83 kilograms. On average, the Darmi variety irrigation effect ranged from 0.63 kilograms $\left(\mathrm{N}_{24}\right)$ to 2.43 kilograms per cubic meter $\left(\mathrm{N}_{16}\right)$ during the given period.
\end{abstract}

UDC Classification: 631.5, DOI: https://doi.org/10.12955/pns.v1.114

Keywords: cotton, irrigation, fertilization, productivity, efficiency factor

\section{Introduction}

Cotton (Gossypium hirsutum L.) is one of the most important industrial crop worldwide. Bulgaria forms the northern boundary of the production of this strategic plant culture. Nevertheless, in recent decades cotton has become a scarce culture due to high cultivation cost.This issue has been further impacted by a decline in the price of processed fiber and by a difficulty to obtain supplies such as fertilizers, chemicals and fuel.On contrary, in recent years the European Union has set higher support frameworks aiming to enhance the financial stability of the cotton industry (AR, 2017). Of the member states of Euro Zone, only Greece, Spain and Bulgaria have been deemed as having suitable climatic conditions.

Previous research demonstrated that temperature is a limiting factor impacting cotton growth. According to Milkovski et al. (1969) temperature of 0 degree Celsius provides optimal conditions for the growth and maturation of cotton. Varieties with short growing period which mature within 120 days and which are also suitable for cultivation in northern latitudes are typical for Bulgaria. Unfavorable culmination of average daily temperature, combined with precipitation deficiency reduced the productive potential of the cotton varieties (Dimitrova, 1995; Dragica et al., 2010; Earl \& Jones, 2018; Stoilova \& Bozhinov, 2004). The ecological plasticity of cotton has been tested outside the country and was considered as a prerequisite for the search of a selection of Bulgarian varieties. For example, experiments conducted in Syria (1995) tested a Bulgarian variety of cotton called Beli Izvor resulting in a record harvest of $5620 \mathrm{~kg} / \mathrm{ha}$, what was deemed as the highest among all tested varieties including American, Greek, Turkish, Spanish (Borero, 1996).

The productivity of cotton differs depending on humidity conditions during the growing season. Even under optimum temperature conditions, humidity presents another dominant factor. Previous research established, that the correlation coefficient between the yield and water supply in May to August 1969 was $r=.76$ (Milkovski et al., 1969). The rising cost of water irrigation and the reducing water resources forced farmers to adapt strategies of irrigation leading to maximum crop yield and efficiency of water use. The introduction of new andmore drought-resistant cotton varieties as well as effective water management aimed to increase the efficiency of irrigation. Leaf index and dry matter harvest increased with escalated use of irrigation water as found in a field study by Dağdelen (2009). From an economic viewpoint, $25.0 \%$ of saving ofirrigation water (T75) resulted in $34.0 \%$ reduction in the net income. However, the net income of the T100 treatment was found to be reasonable in areas with no water shortage.

\footnotetext{
${ }^{1}$ Faculty of Agriculture, Trakia University, Bulgaria, galina.gospodinova37@ googlemail.com

${ }^{2}$ Faculty of Agriculture, Trakia University, Bulgaria, toni_1219@abv.bg

${ }^{3}$ Agricultural University, Plovdiv, Bulgaria, kuneva@au-plovdiv.bg
} 
Another body of research suggests that the parameters of irrigation water such as gravity and drip influenced irrigation efficiency (Ibraginmov et al., 2007). Optimizing the irrigation regime and using drip irrigation (70-70-60\% of field capacity (FC) provided efficiency gains of 35-103\% as compared to furrow irrigation. Cotton yield increased by $10-19 \%$ after supplying water to the root zone of the plant. The effects of water deficiency on quantitative parameters and on harvest quality have been also studied by a number of researchers (Cetin \& Bilgel, 2002; Mahan \& Payton, 2018; Onder et al., 2009; Saldzhiev \& Raykov, 2011; Stoyanova \& Kuneva, 2019; Wanjura et al., 2002; Wang et al., 2011). Accordingly, the low nitrogen $(\mathrm{N})$ level in the solution drastically reduced vegetative growth components, number of bolls, seed cotton and fiber harvest (Malavolta et al., 2004). To this end, Aujla et al. (2005) concluded that reducing the water amount decreased the agronomic efficiency of N. Drip irrigation increased agronomic performance of imported $\mathrm{N}$ as compared to gravity irrigation. Moreover, according to Yang et al. (2012), single fertilization reduced labor costs without impacting the yield as reports in their field study conducted in the Yangtze River Valley in China.

Previous investigations also suggest, that the harvest of cotton transformed biomass (Bange \& Milroy., 2004; Brodrick et al. 2013) which is an important component determining the cotton harvest success through its reproduction (Yang et al., 2011). Thus, the application of biologically active substances increased the resistance of the cotton plants to abiotic factors. Kerby et al. (1993) found that the application of biologically active substances during critical periods of phenological development optimized the balance between vegetative and generative growth. Growth regulators stimulated physiological processes in plants and formed a larger leaf-stem mass (Delchev, 2003). The structural elements yield determined factors such as the rate of fertilization, seeding density and variety, the degree of weeding and soil preparation. Each of these elements of agrotechnics was investigated by a number of researchers (Koleva \& Petrova, 2014; Barakova et al., 2018; Barakova et al., 2019). For instance, Zhao et al. (2010) found a significant correlation between root length density and cotton yield during the flowering stage and bud opening. Trends in the effects of drought on the crops were analyzed by various models predicting the yield of the crop (Wang et al., 2011; Popova et al., 2014; Yang et al., 2015; Dochin et al., 2018; Kostadinov et al., 2019).

Based on the above discussed limitations of previous research, the purpose of this study is to analyze the impact of specific factors of variety and irrigation on cotton yield, and to study the effectiveness of irrigation on the productivity of cotton varieties after adding various amounts of mineral nutrition.

\section{Materials and Methods}

To assess the impact of humidity of soil and fertilizer norm, we conducted a field trial with three varieties of cotton. The field experiment was conducted in within the Faculty of Agriculture, Trakia University, Stara Zagora, Bulgaria in 2018-2019. The region had a planar nature with an elevation height of $169 \mathrm{~m}$. The geographic coordinates were as following; $42^{\circ}$ and $41^{\prime}$ north latitude and $23^{\circ}$ and 19' east longitude GMT (GPS). The experimental field was located in a zone of moderate continental climate of Europe. Data on the climate elements was collected from the National Institute for Meteorology and Hydrology.

The experiment was set up with the following varieties of cotton: Helius, Darmi and Isabell. These varieties are a Bulgarian selection cultivated between 2007-2010. The short vegetation period is characteristic for Bulgarian selection varieties. Helius is characterized by a high yield of unprocessed cotton and produce of fiber and its vegetation period is 131 days. In the Darmi variety, the harvest ratio is about $39.5 \%$. The vegetation period is 116-122 days. The fiber is white medium-fine, with good uniformity, maturity and has a good strength. The Isabell variety launched a new generation of varieties with naturally colored fiber with a high ecological and economic effect. The first variety is characterized by a brown fiber and a high yield (37-38\%). Isabell has a naturally colored tan to cream line, which is short, medium-fine, with good uniformity and extensibility. The vegetation period of this early variety is $109-111$ days.

The study was conducted on a meadow-cinnamic soil type under irrigated and non-irrigated conditions. The power of the soil profile was $103-105 \mathrm{~cm}$, with well formed layers. The humus layer depth ranged between 0-45 (50) cm, while layer B had less power. The soil layer C reached a depth of $103-105 \mathrm{~cm}$. The mechanical composition of the soil was given by a medium sandy loam. The soil density (as measured by the method of Kaczynski) of the surface layer was $1.07 \mathrm{~g} / \mathrm{m}^{3}$ and reached 1.34 
$\mathrm{g} / \mathrm{m}^{3}$ in the $60-80 \mathrm{~cm}$ deep layer. The relative density (given by the pycnometric method) ranged from 2.65 to 2.72 . The marginal field moisture capacity in layers $0-40 \mathrm{~cm}$ was $31.6 \%$. The average stock of humus in the soil was $3.42 \%-4.04 \%$.

The field experience was based on the method of fractional plots in 4 repetitions with the size of the plots being $15 \mathrm{~m}^{2}(1.80 \mathrm{~m} \times 8.34 \mathrm{~m})$. The value of irrigation drip was $75 \%$ FC in soil layers between 0 $50 \mathrm{~cm}$. In the control condition, each cotton variety was left without fertilization and watering. The norms of fertilization and irrigation levels were defined based on previous studies and literary data (Gospodinova et L., 2019.).

To report the occurrance and course of the main phenological phases of cotton growth, we translated biometric measurements and phenological observations during the experiment. The data was statistically processed by MS Excel. The evaluation of the influence power of factors was calculated on Plohinski (Lakin, 1980). It was defined as part of inter-group variation in total variation of the sum of the squares and was calculated as follows:

$$
h_{x}^{2}=\frac{D_{x}}{D_{y}}
$$

where $D_{x}$ - was the sum of the squares of the x factor, $D_{y}$ - presented the total sum of squares (SS). We sought to establish the main effects of both factors (variety and irrigation), as well as their interaction on the yield of the three varieties of cotton.

\section{Results and Discussions}

\section{Agro-climatic conditions}

The climatic conditions during the vegetation of cotton were specific and differed during the two years both in terms of temperature, quantity and distribution of rainfall. Particularly vulnerable were plants grown under conditions of natural water supply. In the formation of cotton harvest, heat and humidity were an important factor for flowering-start and ripening of harvest which occured during the months of July to August.

\begin{tabular}{|c|c|c|c|c|}
\hline Factor & & $\begin{array}{c}\text { Average for the period } \\
1930-2019\end{array}$ & 2018 & 2019 \\
\hline \multirow{2}{*}{$\mathrm{N}$} & $\mathrm{mm}$ & Average (V-X) $299.74 \mathrm{~mm}$ & 347.4 & 274.2 \\
\hline & $\mathrm{P} \%$ & $299.74 \mathrm{~mm}$ & 29.5 & 51.7 \\
\hline \multirow{2}{*}{$\mathrm{T}^{\mathrm{o}}$} & ${ }^{\circ} \mathrm{C}$ & \multirow{2}{*}{ Average $(\mathrm{V}-\mathrm{X}) 1178.0^{\circ} \mathrm{C}$} & 1245.0 & 1246.0 \\
\hline & $\mathrm{P} \%$ & & 90.4 & 91.5 \\
\hline \multirow{2}{*}{$\mathrm{N}$} & $\mathrm{mm}$ & \multirow{2}{*}{ Average (VI-VIII) $156.85 \mathrm{~mm}$} & 187.4 & 171.8 \\
\hline & $\mathrm{P} \%$ & & 72.7 & 68.3 \\
\hline \multirow{2}{*}{$\mathrm{T}^{\mathrm{o}}$} & ${ }^{\circ} \mathrm{C}$ & \multirow{2}{*}{ Average (VI-VIII) $681.7^{\circ} \mathrm{C}$} & 713.0 & 724.0 \\
\hline & $\mathrm{P} \%$ & & 79.3 & 87.1 \\
\hline
\end{tabular}

To determine the probability $(\mathrm{P})$, we used data on precipitation and average daily temperatures from the past 90 years and calculated the provision according to the following formula:

$$
\mathrm{P}=\left(\frac{n-0.3}{m+0.4}\right) * 100
$$

where $m$ is the number of the year in the upstream row, and $n$ is the total number of years in the series. The analysis revealed that cotton grew in conditions with limited resources and unsustainable temperature and moisture. Temperature was crucial for the development and maturation of cotton. The growth and yield of cotton (Gossypium hirsutum L.) were highly inhibited by low temperatures, especially in stages of germination and bud emergence, according to studies by Ashraf (2002). Jakimov et al. (2013) also established the adverse impact of lower temperatures on the cultivation of cotton. In the period from June to September, both years in the exeperiment were characterized by higher than average temperature $1178.0{ }^{\circ} \mathrm{C}$ (values present the average diurnal) with a security of 90.4 and $91.5 \%$ in terms of factors of heat. Durng the two years, we did not measure extremely high temperatures which can damage the development of plants. The increase in temperature leading to a 
decrease in yield had been established by Rishi et al. (2007). Specifically, photosynthetic apparatus studies (Wise et al., 2004) showed that moderately high temperatures $\left(35-42{ }^{\circ} \mathrm{C}\right)$ can cause direct injury to the crops of Pima cotton (Gossypium barbadense) grown under irrigation in the US desert south-west.

Although cotton is a fairly drought tolerant culture, our results showed a responsiveness to optimizing the factors of water. Therefore the analyzes are separated and we focused on the amount and distribution of rainfall. During the period from May to October of the first year, the sufficiency of rainfall was $29.5 \%$ what can be defined as medium wet. With $51.7 \%$ probability of rainfall, the second test year was characterized as medium dry. The amount of rainfall during the first experimental year during the months of great tension of climatic factors from July to August was $102.2 \mathrm{~mm}$.

The total amount of rainfall registered in 2019 was $63.1 \mathrm{~mm}$. An uneven distribution of rainfall within ten-day periods was typical for both testing years. In line with the results of a field study, in the second experimental year, the water deficit impacted the moisture phenophase critical for the start of flowermaturing. This adversely affected the generative development and productivity of cotton, despite the plant is characterized as a relatively drought resistant crop. The relationship between the total amount of rain and its effectiveness is complex and it depends on the amount and timing of rainfall relative to the crop. Mahan \& Payton (2018) established a relationship between rain and harvest ratio as relatively weak with an $\mathrm{r}^{2}=.35$. The efficient use of rainfall continues to be examined especially in areas with unstable moisturizing.

The results of the two-factor analysis of variance (ANOVA) are presented in tables 2 and 3 displaying the proportion of cotton flowering of three varieties (A) under different irrigation (B) schedules during 2018 and 2019.

Table 2. Two-factor dispersion analysis of the factors: A - variety and B - irrigation for cotton flowering under irrigation conditions in 2018.

\begin{tabular}{|l|c|c|c|c|c|c|c|}
\hline \multicolumn{1}{|c|}{ Source of variation } & $S S$ & $d f$ & $M S$ & $F$ & $P$-value & $F$ crit & Power of influence \\
\hline Variety (A) n.s. & 48864.13 & 2 & 24432.06 & 4.90 & .02 & 3.40 & $9 \%$ \\
\hline Irrigation (B)** & 358197.7 & 3 & 119399.23 & 23.95 & .00 & 3.01 & $64 \%$ \\
\hline Interaction (AxB) n.s. & 45454.38 & 6 & 7575.73 & 1.52 & .21 & 2.51 & $8 \%$ \\
\hline Errors & 119643.5 & 24 & 4985.15 & & & & $19 \%$ \\
\hline$* * *, * *, *$ - significant at $\mathrm{p} \leq 0.001, \mathrm{p} \leq 0.01$ and $\mathrm{p} \leq 0.05 ;$ n.s. - Insignificant \\
\hline
\end{tabular}

Table 3. Two-factor dispersion analysis of the factors: A - variety and B - irrigation for cotton flowering under irrigation conditions in 2019.

\begin{tabular}{|l|c|c|c|c|c|c|c|}
\hline \multicolumn{1}{|c|}{ Source of variation } & $S S$ & $D f$ & $M S$ & $F$ & $P$-value & $F$ crit & Power of influence \\
\hline Variety (A) n.s. & 120559.06 & 2 & 60279.53 & 3.53 & .04 & 3.40 & $12 \%$ \\
\hline Irrigation (B)*** & 411138.75 & 3 & 137046.25 & 8.03 & .00 & 3.01 & $41 \%$ \\
\hline Interaction (AxB) n.s. & 55650.50 & 6 & 9275.08 & 0.54 & .77 & 2.51 & $6 \%$ \\
\hline Errors & 409653.33 & 24 & 17068.89 & & & & $41 \%$ \\
\hline ***, **, * significant at $\leq 0.001, \mathrm{p} \leq 0.01$ and $\mathrm{p} \leq 0.05 ;$ n.s. - Insignificant \\
Source: Authors
\end{tabular}

There was a main effect of "irrigation", $F(2,24)=23.95, \mathrm{p}<.001$ followed by the main effect of "variety" $\mathrm{F}(2,24)=4.90, \mathrm{p}=.016$. The interaction between the two factors was not significant (Table. 2). In 2019 the highest "flowering" indicator (Table 3) by a main effect of irrigation $(F(2,24)=$ 8.03, $\mathrm{p}<.001)$. Secondly, the main effect of variety and the interaction of the two factors remained insignificant. These results suggest that while irrigation is an important factor impacting the cotton the "flowering" indicator, the role of variety and the interaction between irrigation and variety remains less pronounced.

\section{Cotton productivity and irrigation efficiency}

As a result of the manifestation of specific climatic conditions during the two years, the corresponding yields were obtained in accordance with the methodology and the irrigation standards implemented. The data presented in Table 4 shows the obtained produce and irrigation parameters implemented to the studied cotton varieties. During the first year of testing, high yields were determined by the 
influence of natural water supply. Better humidification in 2018 provided a $27.4 \%$ higher helius harvest on average as compared to 2019 , which was characterized by average dryness. This trend was also confirmed by Aujla et al. (2005). During 2018 considered as a humid year, the amount of rainfall between flowering and betting of the buds provided enough accessible moisture. The watering and higher fertilisation background created good conditions for the formation of a large vegetative mass. Additional harvest was only obtained for the Hellius Zero Fertilizer variant. The Darmi variety formed an additional harvest of 111.7 to $133.4 \mathrm{~kg} / \mathrm{ha}$ in fertilization with $\mathrm{N}_{0}$ and $\mathrm{N}_{16}$. However, other researchers concluded that the optimum rate of $\mathrm{N}$ for the maximum accumulation of the cotton biomass and forming the yield is differs from the potential yield (Boquet, 2005; Yang et al., 2011).

The color dyed variety Isabell was responsive to irrigation and formed a further extraction at three levels of fertilization $\left(\mathrm{N}_{0} ; 8 ; 16\right)$. With the high dose of $\mathrm{N}$ and under the influence of the given irrigations, it developed a greater vegetative mass. Particular buds remained unhatched and as a result, it reduced the productivity of cotton. The coefficient of performance is the ratio between the additional yield and the actual irrigation rate. Efficiency values varied widely across the three varieties, depending on water supply and fertilizer levels. The achieved irrigation rate during the year with better water supply did not lead to increased yield in any of the cotton variants. Cetin \& Bilgel (2002) also found that watering resulted in a lower overall cotton harvest. Accordingly, Earl \& Jones (2018) developed a model to optimize irrigation in years with sufficient rainfall. The 'Isabell' variety was responsive to the supplied irrigation water of $300 \mathrm{~mm}$ across two irrigations. At fertilization levels from $\mathrm{N}_{0}$ to $\mathrm{N}_{16}$ and under the influence of the additionally supplied irrigation water, an additional yield was obtained, with an efficiency coefficient of 0.19-1.04.

Table 4. Irrigation parameters, productivity and the effect of irrigation on three cotton varieties, for the period 2018-2019, for the Stara Zagora

\begin{tabular}{|c|c|c|c|c|c|c|}
\hline \multicolumn{2}{|r|}{ Variant } & \multirow{2}{*}{ Variety } & \multirow{2}{*}{$\begin{array}{c}\text { Irrigation norm } \\
\mathrm{mm}\end{array}$} & \multirow{2}{*}{$\begin{array}{l}\text { Yield } \\
\mathrm{kg} / \mathrm{ha}\end{array}$} & \multirow{2}{*}{$\begin{array}{c}\text { Additional yield } \\
\mathrm{kg} / \mathrm{ha}\end{array}$} & \multirow{2}{*}{ Efficiency factor (EF) } \\
\hline № & Fertilization rate & & & & & \\
\hline \multicolumn{7}{|c|}{2018} \\
\hline 1 & $\mathrm{~N}_{0}$ & \multirow{4}{*}{$\stackrel{0}{\frac{0}{0}}$} & 300 & 1541.8 & 133.5 & 0.45 \\
\hline 2 & $\mathrm{~N}_{8}$ & & 300 & 1496.7 & -625.0 & -2.08 \\
\hline 3 & $\mathrm{~N}_{16}$ & & 300 & 1745.1 & -653.4 & -2.18 \\
\hline 4 & $\mathrm{~N}_{24}$ & & 300 & 153.4 & -458.3 & -1.53 \\
\hline 5 & $\mathrm{~N}_{0}$ & \multirow{4}{*}{ 鴣 } & 300 & 1891.8 & 133.4 & 0.44 \\
\hline 6 & $\mathrm{~N}_{8}$ & & 300 & 1996.7 & -65.0 & -0.22 \\
\hline 7 & $\mathrm{~N}_{16}$ & & 300 & 2220.1 & 111.7 & 0.37 \\
\hline 8 & $\mathrm{~N}_{24}$ & & 300 & 1965.1 & -318.4 & -1.06 \\
\hline 9 & $\mathrm{~N}_{0}$ & \multirow{4}{*}{ 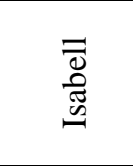 } & 300 & 1790.1 & 313.4 & 1.04 \\
\hline 10 & $\mathrm{~N}_{8}$ & & 300 & 2171.8 & 265.0 & 0.88 \\
\hline 11 & $\mathrm{~N}_{16}$ & & 300 & 1901.7 & 56.7 & 0.19 \\
\hline 12 & $\mathrm{~N}_{24}$ & & 300 & 1795.1 & -224.8 & -0.75 \\
\hline \multicolumn{7}{|c|}{2019} \\
\hline 1 & $\mathrm{~N}_{0}$ & \multirow{4}{*}{$\stackrel{\frac{0}{\pi}}{\frac{0}{\pi}}$} & 600 & 1668.7 & 267.9 & 0.45 \\
\hline 2 & $\mathrm{~N}_{8}$ & & 600 & 1870.0 & 400.8 & 0.67 \\
\hline 3 & $\mathrm{~N}_{16}$ & & 600 & 1817.0 & 212.3 & 0.35 \\
\hline 4 & $\mathrm{~N}_{24}$ & & 600 & 1758.9 & 320.4 & 0.53 \\
\hline 5 & $\mathrm{~N}_{0}$ & \multirow{4}{*}{ 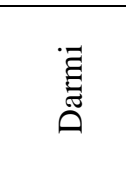 } & 600 & 1793.0 & 277.3 & 0.46 \\
\hline 6 & $\mathrm{~N}_{8}$ & & 600 & 1590.4 & 200.9 & 0.33 \\
\hline 7 & $\mathrm{~N}_{16}$ & & 600 & 1954.6 & 276.1 & 0.46 \\
\hline 8 & $\mathrm{~N}_{24}$ & & 600 & 1828.9 & 272.2 & 0.45 \\
\hline 9 & $\mathrm{~N}_{0}$ & \multirow{4}{*}{$\begin{array}{l}\overline{\overline{0}} \\
\text { 芯 }\end{array}$} & 600 & 1597.6 & 146.8 & 0.24 \\
\hline 10 & $\mathrm{~N}_{8}$ & & 600 & 1892.6 & 347.7 & 0.58 \\
\hline 11 & $\mathrm{~N}_{16}$ & & 600 & 1869.4 & 320.4 & 0.53 \\
\hline 12 & $\mathrm{~N}_{24}$ & & 600 & 1765.2 & 266.2 & 0.44 \\
\hline
\end{tabular}

The additional harvest ratio obtained during the second experimental year was higher. The applied irrigation rate $(600 \mathrm{~mm})$ reduced the negative effect of water shortage on the plant biomass growth and flower staining. The overall impact of fertilization and irrigation during the dry year of 2019 provided 
higher additional yield. These results were also supported by Dağdelen (2009).The efficiency ratio was significantly higher than during the first year. The optimization of provided humidification and the stable temperature factor resulted in an additional harvest of $146.8 \mathrm{~kg} / \mathrm{ha}$ to $400.8 \mathrm{~kg} / \mathrm{ha}$. After importing $\mathrm{N}_{8}$ to the Helius and Isabell cotton varieties, they provided the highest additional yield. The efficiency of irrigation water was 0.67 for Helius and 0.58 for Isabel. The Darmi variety results at different fertilization levels were set at narrow limits and the coefficient of efficiency varied from 0.33 to 0.46 .

Furthermore, the results showed a heterogeneous manifestation of the water factor in each variety. The efficiency of the use of irrigation water depended on the climatic factors. The recorded additional harvest ratio in after natural water supply reduced the effect of irrigation water. Investigating the optimization of the water amount used on the cotton varieties enabled to precisely establish the effect of irrigation water. Accordingly, the parameters of the irrigation water (AIW) for cotton (Gossypium hirsutum L.) in context of the climate circumstances were also established by García-Vila et al. (2009).

The effect of irrigation, expressed as a harvest ratio per unit of irrigation water varied greatly over the years. At zero fertilization Helius, each cubic meter of water carried 2.24 kilograms of cotton, averaged over the two years. Over the year with unfavourable climatic factors, the fertilization with $\mathrm{N}_{16}$ for each cubic meter of water carried $2.83 \mathrm{~kg}$ of cotton. The effect of irrigation water on Darmi variety was relatively uniform when providing a sufficient quantity of readily available water. Artificially brought water supplied in the form of 4 irrigations resulted in collecting 2.16 to 2.20 kilograms of cotton per cubic meter. Against the background of fertilization with $\mathrm{N}$ fertilizer at a dose of $\mathrm{N}_{8}$, each cubic meter irrigation water brought $2.99 \mathrm{~kg}$ of cotton. The average harvest for the period of irrigation of Darmi ranged from $0.63\left(\mathrm{~N}_{24}\right)$ to $2.43\left(\mathrm{~N}_{16}\right)$ kilograms per cubic meter. The high additional harvest in 2018 considered as a wet year, did not contribute to the effect of irrigation. The highest irrigation water use efficiency was obtained with reduced $1 / 2$ irrigation rate (Onder et al., 2009). The Dye Isabell cotton type was characterized by varying influence of irrigation water under different levels of fertilization. The highest average effect of irrigation during the given period was registered follwoing fertilization by $\mathrm{N}_{16}$.

\section{Conclusions}

According to the two-factor ANOVA, with sorting and irrigation as factors, we detected highly significant effects $(\mathrm{p}<.001)$, with irrigation showing the greatest influence on the yield. Furthermore, the strongest influence on the differences in cotton "flowering" were given by cotton variety (64\%) in 2018 , followed by this factor $(41 \%)$ for 2019 . The natural water supply in the first trial year provided high additional harvest rate. The values of the additional produce in the second trial year were higher. In all three cotton varieties, optimizing water supply provided an increase in additional yield at times.

The coefficient of efficiency of irrigation water varied depending on the varieties and the levels of fertilization. The highest values of the ratio were recorded at fertilization to $\mathrm{N}_{8}$ in cultivar Helius, (EF $=0.67)$ and in Isabelle is calculated $(\mathrm{EF}=0.58)$. The effect of irrigation, expressed as yield per unit of irrigation water varied greatly over the years. Optimizing the water supply and fertilizing with $\mathrm{N}_{16}$ provided 2.83 kilograms per cube. The different influence of irrigation water on different fertilization levels was reported for the Isabell cotton variety. On average, the highest irrigation effect was registered after using the $\mathrm{N}_{16}$ fertilization variant.

\section{References}

Aujla, M. S,Thind, H.S.\& Buttar,G.S. (2005). Cotton yield and water use efficiency at various levels of water and N through drip irrigation under two methods of planting. Agricultural Water Management, 71(2), 167-179.

Ashraf, M. (2002). Salt tolerance of cotton: some new advances. Critical Reviews in Plant Sciences 21(1), 1- 32.

Annual report on the state and development of agriculture-Agricultural report (AR) - 2019, $246 \mathrm{p}$.

Annual Report - 2017. Economic Development And Policies In Bulgaria: Evaluations And Expectations

Bulgarian Academy of Sciences. Institute for Economic Research. Sofia, 203 p.

Borero, A. (1996). Report on Variety Trials. Proceedings of consultation, CIRRAD, Montpelier, France, 37-38.

Boquet, D. (2005). Cotton in Ultra- Narrow Row Spacing: Plant Density and Nitrogen Fertilizer Rates. Agronomy Journal97(1), 279-287.

Barakova, T., Delchev, G., Valkova,N., Sturzu, R., Meluca,C.,\& Nistor, T. (2018). Influence of foliar antibroadleaved herbicides on cotton seed germination (Gossypium hirsutum L.). Romanian Agricultural Research, 35, 193-201. 
Barakova, T.,. Delchev, G., Valkova, N., Sturzu, R., Meluca, C., \& Cojocaru, J. (2019). Effect of some herbicides and their mixtures with growth regulator and foliar fertilizer on protein content in cotton (Gossypium hirsutum L.) seeds. Romanian Agricultural Research, 36, 187-194.

Bange, M. P.\& Milroy, S. P. (2004). Growth and dry matter partitioning of diverse cotton genotypes. Field Crops Research, 87(1), 73-87.

Brodrick, R., Bange, M. P., Milroy, S. P., \& Hammer, G. L. (2013). Physiological determinants of high yielding ultra-narrow row cotton: Canopy development and radiation use efficiency. Field Crops Research, 148 86-94.

Cetin, O., Bilgel, L. (2002). Effects of different irrigation methods on shedding and yield of cotton. Agriculturel Water Management, 54(1), 1-15.

García-Vila M., Fereres, E., Mateos, L., Orgaz, F.,\& Steduto, P. (2009). Deficit Irrigation Optimization of Cotton with Aqua Crop. Agronomy Journal,101(3),477-487. https://doi.org/10.2134/agronj2008.0179s

Gospodinova, G. \& Panayotova G. (2019). Strategies for nitrogen fertilization of cotton (Gossypium hirsutum L.). Bulgarian Journal of Agricultural Science, 25 (Suppl. 3), 59-67.

Dimitrova, L. (1995). Regulation of cotton growth and development, Cotton production. Sofia, 234

Delchev, G. (2003). The use of growth regulators and complex leaf fertilizers on a different background of mineral fertilization in durum wheat (Triticum Durum Desf.). Thesis, Sofia, NCAS, 184 p.

Dağdelen, N., Başal, H., Yılmaz, bE.,,Gürbüz, aT., \& .Akçaya, aS (2009). Different drip irrigation regimes affect cotton yield, water use efficiency and fiber quality in western Turkey. Agriculturel Water Management, 96(1), 111-120.

Dragica, S., Spasov, D., Mihailov, L., Stoilova, A.\& Valkova, N., (2010). Test results of new Bulgarian cotton varieties in Strumica, Macedonia. Field Crops Studies, VI(3), 387-393.

Dochin, K., Kuneva, V., Ivanova, A.,\& Iliev, I.(2018). Current state of phytoplankton in Batak reservoir (Southwestern Bulgaria), Bulgarian Journal of Agriculture Science, 24 (4), 686-697. (Web of science)

Vories, Earl D. Jones \& A.S. (2018). Influence of Irrigation Pattern on Effectiveness of Furrow Irrigation of Cotton. Agronomy and Soils, 153-161.

Ibraginmov N, Evett S. R., Esanbekov Y, Kamilov B. S., Mirzaev L.,\& Lamers J. P.A. (2007). Water use efficiency of irrigated cotton in Uzbekistan under drip and furrow irrigation. Agriculture Water Management, 90 (1-2),112-120.

Jakimov, D., Pirikliev, D., Kocevski, V., \& Gjeorgjievski, M.(2013). The impact of climatic factors on the length of vegetation retained in some varieties of cotton in Strumica. Journal of Agriculture and Plant Sciences, 22 [S.1.], 153-161, ISSN 2545-4455. Retrieved from http://js.ugd.edu.mk/index.php/YFA/article/view/292

Kerby, T. A., Horrocks, R.D. \& Plant, R. E. (1993). Plant Monitoring to Quantity Vegetative Vigor. Cotton Physiology Conferences. Proceedings Beltwide Cotton Conference. National Cotton Council, Memphis.

Koleva, M. \& Petrova, I. (2014). Effect on the yield and quality fibres of some new biologically active substances applied during the cotton flowering. Science \& Technologies. Plant studies, IV, (6), 175-179.

Kostadinov, K., Filipov, S. Valcheva, Kuneva, V. (2019). Influence of biological fertilization on vegetative behavior and productivity of greenhouse eggplant. Scientific Papers, Series B. Horticulture, LXIII(1), 297-305. (Web of science)

Lakin, G. F.(1980). Biometrics, Higher School, Moscow, 293 p.

Milkovski, I., Eninov, K.\& Herchovich, E., (1969). Soil and climatic zoning of the main arable crops. Publishing House of the Bulgarian Academy of Sciences, 331

Malavolta, E., Nogueira, N. G. , Heinrichs, L.R., Higashi, E. N., Rodríguez, V., Guerra, E., C. de Oliveira, S., \& Cabral, C.P.(2004). Evaluation of Nutritional Status of the Cotton Plant with Respect to Nitrogen. Journal of Plant Nutrition, 32 (8), $1007-1019$

Mahan, J., \& Payton, P. (2018). Design and Implementation of a Rainfed Matrix for Cotton. Agriculture, 8(12), 193. https://doi.org/10.3390/agriculture8120193

Onder D., Akiscan, Y., Onder,S. \& Mert (2009). Effect of different irrigation water level on cotton yield and yield components. African Journal of Biotechnology, 8 (8), 1536-1544.

Popova, Z., Ivanova, M., Martins, D., Pereira, S., Doneva, K., Alexandrov,V.\& Kercheva, M. (2014). Vulnerability of Bulgarian agriculture to drought and climate variability with focus on rainfed maize systems. Natural Hazards, 74 (2), 865886 . https://doi.org/10.1007/s11069-014-1215-3

Rishi P. Singh, Vara Prasad, P.V., Sunita, K., Giri, S. N\& RajaReddy, K. (2007). Influence of High Temperature and Breeding for Heat Tolerance in Cotton: A Review. Advances in Agronomy, 93, 313-385.

Stoilova, A.\& Bozhinov, M. (2004). Performance of Mediterrannean Cotton Varieties in Bulgaria during 2001-2003. Proceedings-Plenary Meeting of Inter-Regional Cooperative Research Network on Cotton, 29 September-2 October, Cotton and Industrial Plants Institute, Thessaloniki, Greece, 47-52.

Saldzhiev I.\& Raykov, S., (2011). Wide-row cultivation of cotton under irrigation. Field Crops Studies, VII(2), 293-298.

Stoyanova A., \& Kuneva, V.,(2019). Evaluation of the influence of irrigation and fertilization on the content of some biochemical colour compounds in tomatoes, greenhouse production by mathematical approach. Bulgarian Journal of Agricultural Science, 25 (Supplement 3), 29-34.

Wanjura, D. F, Upchurch,D. R., Mahan, J.R.\& J. J Burke (2002). Cotton yield and applied water relationships under drip irrigation. Agricultural Water Management,55(3), 217-237. 
Wang, R., Kanga, Y., S. Wan, S.,W. Hu, W., S. Liu, S., \& Liu, S., (2011). Salt distribution and the growth of cotton under different drip irrigation regimes in a saline area. Agricultural Water Management, 100(1), 58-69.

Wise, R. R., Olson, A. J., Schrader, S. M. \& Sharkey, T.D. (2004). Electron transport is the functional limitation of photosynthesis in field- grown Pima cotton plants at high temperature. Plant, Cell \& EnvironmentVolume 27(6), 717-724. Yang G, Tanga, H., Tong, J., Niea, X. \& Zhang (2012). Effect of fertilization frequency on cotton yield and biomass accumulation. Field Crops Research,125, 161-166.

Yang C., Luo,Y., Sun, L.\& Wu, N., (2015). Effect of Deficit Irrigation on the Growth, Water Use Characteristics and Yield of Cotton in Arid Northwest China. Pedosphere,25(6), 910-924.

Yang G., Tang, H.,Nie, Y.,Zhang, X.,(2011). Responses of cotton growth, yield, and biomass to nitrogen split application ratio. European Journal of Agronomy, 35, (3), 164-170.

Zhao ChengYi, Ying Yu Y. A. N., Yilihamu Yimamu, Juyan, L. I., Zhimin Z. H. A. O., \& Laosheng W. U. (2010). Effects of soil moisture on cotton root length density and yield under drip irrigation with plastic mulch in Aksu Oasis farmland. Journal of Arid Land, 2(4), 243-249. 